\title{
Verbanning uit het semipublieke domein
}

\section{Toegangsverboden in juridisch perspectief}

\section{Mandy van Rooij"}

Wie in het weekend in het voetbalstadion overlast veroorzaakt en wangedrag laat zien, heeft grote kans dat hij de eerstvolgende wedstrijd al moet missen vanwege een stadionverbod. Het sanctiestelsel dat de Koninklijke Nederlandse Voetbalbond (KNVB) in de jaren negentig optuigde, werkt op volle snelheid; in het seizoen 2016/2017 legde de KNVB 569 stadionverboden op wegens voetbalgerelateerde strafbare feiten en ander wangedrag in het kader van wedstrijden (CIV 2017, p. 45). Het gaat hier om stadionverboden met een landelijke dekking: één toegangsverbod dat geldt voor alle voetbalstadions in Nederland. In de winkel- en horecabranche en het openbaar vervoer zijn collectieve ontzeggingen eveneens gebruik geworden. Dit type collectieve toegangsverboden is ontstaan als particulier initiatief. Na positieve ervaringen van Haagse winkeliers met de collectieve winkelontzegging stelde het toenmalige Hoofdbedrijfschap Detailhandel een modelprotocol op voor landelijk gebruik (Wesselink e.a. 2009; Van Rooij 2014). Koninklijke Horeca Nederland ontwikkelde in dezelfde periode een model voor collectieve horecaontzeggingen. In de strijd tegen voetbalhooligans werkte de KNVB al langer met de landelijke stadionverboden. Arriva en gemeentelijke vervoersbedrijven experimenteerden met reisverboden (Van Steden e.a. 2012).

Winkels, horecagelegenheden, voetbalevenementen, openbaar vervoer en stations zijn voor het publiek toegankelijke plaatsen die door particuliere entiteiten beheerd worden. In principe staat de toegang

* Mr. dr. A.E. van Rooij verdedigde in 2017 aan de Vrije Universiteit Amsterdam haar proefschrift Orde in het semipublieke domein. Particuliere en publiek-private orderegulering in juridisch perspectief, uitgegeven bij Boom juridisch (Den Haag). Deze bijdrage is gebaseerd op dit promotieonderzoek. Inmiddels is zij werkzaam als wetgevingsjurist bij het ministerie van Binnenlandse Zaken en Koninkrijksrelaties en verbonden als onderzoeker aan de Faculteit Rechtsgeleerdheid van de VU. 
voor iedereen open, zonder aanzien des persoons, maar beheerders kunnen voorwaarden stellen aan de toegang tot hun domein. Dat maakt dit domein semipubliek van aard. In deze bijdrage plaats ik de verbanning uit het semipublieke domein in een juridisch perspectief. Eerst licht ik toe welke soorten toegangsverboden te onderscheiden zijn. Daarna bespreek ik de juridische basis. Vervolgens komt aan de orde welke juridische waarborgen er zijn om willekeur en misbruik te voorkomen. Ten slotte ga ik in op de rechtsbescherming en de aanvullende rol van klachtencommissies.

\section{Toegangsverboden in allerlei soorten en maten}

Stadionverboden, winkel- en horecaontzeggingen en reis- en stationsverboden zijn er in verschillende soorten en maten. Ten eerste is een onderscheid te maken tussen een individuele en collectieve ontzegging. In het geval van een individuele ontzegging wordt de betrokkene uitgesloten van één plaats, veelal waar hij de overlast pleegde. Een collectieve ontzegging geldt ook voor andere plaatsen, die worden beheerd door andere particuliere beheerders. Bij de landelijke stadionverboden wordt dit gerealiseerd via de KNVB, waarbij alle betaaldvoetbalorganisaties zijn aangesloten. In de horeca- en winkelbranche vormen ondernemers op lokaal niveau een samenwerkingsverband en wordt één collectief verbod geacht te zijn uitgereikt namens alle deelnemende ondernemers. In de binnenstad van Den Haag deden ongeveer 450 winkeliers mee (Wesselink e.a. 2009). In de tweede plaats is een onderscheid te maken tussen een verwijderbevel en een toegangsverbod. Een verwijderbevel houdt in dat de overlastgever wordt verzocht onmiddellijk de zaak te verlaten. Een toegangsverbod werkt door in de toekomst; een individu wordt voor een bepaalde tijd uitgesloten van toegang en gebruik. Om een collectief en langdurig verbod te kunnen handhaven, worden de gegevens van de verbannen betrokkene, inclusief foto, in de regel opgenomen in een database die de beheerder en zijn veiligheidspersoneel kunnen raadplegen.

Vervolgens is er een verschil tussen de toegangsverboden die in een zuiver particulier verband worden uitgevoerd en de toegangsverboden die deel uitmaken van een publiek-privaat samenwerkingsverband. In het laatste geval leggen de samenwerkende publieke en private partijen afspraken over de uitvoering van de collectieve ontzegging vast in 
een convenant of protocol. Naast ondernemers nemen de gemeente, het Openbaar Ministerie (OM) en de politie taken op zich. Bij deze vorm van publiek-private samenwerking behouden deelnemende partijen hun eigen (juridische) identiteit en verantwoordelijkheid: particulieren maken gebruik van hun privaatrechtelijke instrumenten om de orde in het publiek toegankelijke domein te handhaven en de overheid gebruikt haar publiekrechtelijke bevoegdheden (Hoogenboom \& Muller 2002).

De verzameling en uitwisseling van informatie is een cruciaal onderdeel van publiek-private samenwerking. Gegevensuitwisseling zorgt ervoor dat alle partners meer weten en dus eerder kunnen overgaan tot sanctionering dan wanneer zij zelfstandig - met alleen eigen informatie - zouden opereren. Eén plus één is zo meer dan twee. Het landelijk stadionverbod wordt bijvoorbeeld mede mogelijk gemaakt door het OM, dat de KNVB via het Voetbal Volg Systeem informatie verstrekt over aanhoudingen wegens voetbalgerelateerde strafbare feiten. ${ }^{1}$ De KNVB legt op basis van die informatie stadionverboden op. In het seizoen 2016/2017 gebeurde dat in 336 van de 569 gevallen (CIV 2017, p. 45).

Een ander voorbeeld is de bijstand die de politie verleent in het kader van winkelontzeggingen door inzage in het identiteitsbewijs van de betrokkene te vorderen, als deze niet vrijwillig zijn gegevens aan de winkelier heeft verstrekt ten behoeve van de database. De politie mag inzage vorderen in geval van overlastgevend gedrag dat strafbaar is of een verstoring van de openbare orde. ${ }^{2}$ De politie mag de verkregen informatie daarna aan ondernemers verstrekken in het kader van een duurzaam samenwerkingsverband. ${ }^{3}$

Een laatste vorm van samenwerking is dat de politie de toegangsverboden oplegt namens de private partners. De gedachte is hier dat van de politie meer gezag uitgaat dan van een particuliere ondernemer. In een zaak over een algemeen caféverbod voor de binnenstad van Sittard dat was uitgereikt door de wijkagent oordeelde de Afdeling bestuursrechtspraak van de Raad van State dat de agent namens de ondernemers handelde; het caféverbod werd beschouwd als een private sanctie. ${ }^{4}$ Het College van Beroep voor het bedrijfsleven (CBb)

1 De basis voor de verstrekking is art. 39f van de Wet justitiële en strafvorderlijke gegevens.

2 Art. 2 van de Wet op de identificatieplicht.

3 Art. 20 van de Wet politiegegevens.

4 ABRvS 18 december 2013, ECLI:NL:RVS:2013:2473, Gst. 2014/31, m.nt. Van Rooij, r.o. 4.1. Vgl. Hof 's-Hertogenbosch 28 april 2016, ECLI:NL:GHSHE:2016:1675, r.o. C2. 
kwam tot eenzelfde redenering ten aanzien van een ov-verbod dat de politie had opgelegd, namens de NS, als private eigenaar van het station en de vervoersmiddelen waartoe de toegang wordt ontzegd. ${ }^{5}$ De toegangsverboden tot het semipublieke domein zijn ten slotte te onderscheiden van de 'reguliere' publiekrechtelijke gebiedsverboden die de burgemeester kan opleggen in het geval van een verstoring van de openbare orde op grond van de Gemeentewet of algemene plaatselijke verordening (Brouwer \& Schilder 2007). Ook de strafrechter en het OM kunnen op grond van strafwetgeving gebiedsverboden opleggen voor de openbare ruimte (Jue-Volker 2016). De publieke gebiedsverboden kunnen eveneens het effect hebben dat een betrokkene niet meer naar voetbalwedstrijden mag gaan en wordt verbannen uit het uitgaans-, winkel- en stationsgebied waarvoor het gebiedsverbod geldt. Een wezenlijk verschil is echter dat het hier gaat om de exclusieve publiekrechtelijke bevoegdheid om de toegang tot het gehele publieke domein te verbieden, waaronder ook de openbare weg.

\section{Juridische basis en aard van de toegangsverboden}

Voor de toegangsverboden tot het semipublieke domein zijn drie verschillende juridische grondslagen aan te wijzen. In de eerste plaats kunnen particuliere beheerders een toegangsverbod baseren op hun huisrecht, het van een eigendomsrecht afgeleid gebruiksrecht op de ruimte. Het huisrecht is exclusief, en dat houdt in dat de rechthebbende een (overlastgevende) derde het gebruik van zijn zaak mag weigeren. ${ }^{6}$ Strafrechtelijk wordt het huisrecht kracht bijgezet door strafbaarstelling van huisvredebreuk. ${ }^{7}$ Als een banneling het toegangsverbod overtreedt, kan hij daarvoor strafrechtelijk vervolgd worden, zelfs als hij per abuis toch is binnengelaten door het personeel. ${ }^{8}$

Een tweede juridische basis biedt de overeenkomst, waarin contractueel is vastgelegd dat het toegangsverbod als een sanctie opgelegd kan worden. Dat is bijvoorbeeld het geval bij de aanschaf van een toegangskaart voor een voetbalwedstrijd, waarbij de KNVB omvangrijke algemene voorwaarden van toepassing heeft verklaard. ${ }^{9}$ In de KNVB

5 CBb 16 augustus 2017, ECLI:NL:CBB:2017:349 en 350.

6 Art. 5:1 lid 2 BW.

7 Art. 138 van het Wetboek van Strafrecht (Sr).

8 HR 22 februari 2011, ECLI:NL:HR:2011:BO8001, NJ 2011/105, r.o. 3.2.3 en 3.3.1.

9 Art. 6:217 jo. art. 6:232 BW. 
Standaardvoorwaarden zijn op gedetailleerde wijze allerlei gedragsregels genoemd en op de overtreding daarvan staan een landelijk stadionverbod en een private boete van $€ 450 .{ }^{10}$ Volgens de Standaardvoorwaarden kan zelfs een stadionverbod worden opgelegd wegens 'voetbalgerelateerd wangedrag' buiten het stadion, zolang het gedrag in het kader van de wedstrijd plaatsvindt. Te denken valt aan een vechtpartij in de binnenstad tussen rivaliserende voetbalsupporters, na afloop van een wedstrijd. Op die manier reguleert de KNVB ook gedragingen buiten het semipublieke domein.

Een toegangsverbod is tegelijkertijd ook te beschouwen als een zwarte lijst: 'een waarschuwings- of signaleringslijst waarop personen staan vermeld met wie een bedrijf, organisatie of instelling (tijdelijk) geen zaken wil doen, of alleen onder nadere voorwaarden' (Kabel 2007, p. 227). ${ }^{11}$ Met een collectieve ontzegging geeft een groep ondernemers in essentie aan dat zij geen zaken meer willen doen met de betrokkene.

De derde juridische grondslag doet zich voor in het openbaar vervoer. Op zichzelf kunnen vervoerders en de NS als eigenaar van de stations ook gebruik maken van hun huisrecht of algemene voorwaarden om overlastgevers te weren. Daarnaast bevat de Wet personenvervoer 2000 (Wp 2000) sinds 2015 een expliciete wettelijke grondslag voor het opleggen van een langdurig reis- of verblijfsverbod, in het geval van gedragingen waarmee door de reiziger 'de orde, rust, veiligheid of een goede bedrijfsgang wordt of kan worden verstoord'. ${ }^{12}$ De wetgever beoogde een instrument te creëren dat naast de bestaande privaatrechtelijke mogelijkheden zou zorgen voor een beter op elkaar afgestemde aanpak, waarmee ernstige en structurele overlast in het openbaar vervoer aangepakt kan worden. ${ }^{13}$

In de wetsgeschiedenis blijft onduidelijk of de ov-verboden publiek of privaat van aard zouden zijn. De bevoegdheid is niet neergelegd bij de vervoerder of eigenaar, maar bij de conducteurs en controleurs in hun (publieke) hoedanigheid als buitengewoon opsporingsambtenaar. Bovendien is de bevoegdheid opgenomen in de paragraaf getiteld

10 Art. 10.2 KNVB Standaardvoorwaarden, te raadplegen via: www.knvb.nl. Op de overtreding van stadionverboden staan ook geldboetes, die kunnen oplopen tot $€ 2.000$ per overtreding.

11 Zie voor meer voorbeelden het themadossier zwarte lijsten op www.autoriteitpersoonsgegevens.nl.

12 Art. 98 lid 2 jo. art. 72 Wp 2000.

13 Kamerstukken I/ 2013/14, 33904, 3, p. 21. 
'Dwang- en strafbepalingen'. ${ }^{14}$ Ik meen dat daarom de verboden in het openbaar vervoer die zijn opgelegd op grond van de Wp 2000 zouden moeten kwalificeren als een publiekrechtelijke rechtshandeling en daarmee als een besluit in de zin van de Algemene wet bestuursrecht. De juridische basis is dan immers een exclusieve bevoegdheidsgrondslag in de wet en niet het algemene privaatrechtelijke huisrecht of een contract. Het $\mathrm{CBb}$ oordeelde onlangs echter ten aanzien van ov-verboden die werden gebaseerd op de Wp 2000, dat alsnog ervan moet worden uitgegaan dat hier wordt gehandeld namens de private vervoerder en dat daarom sprake is van een privaatrechtelijke rechtshandeling. ${ }^{15}$ Deze redenering past mijns inziens niet bij wat de wetgever bij de uitbreiding van de Wp 2000 heeft beoogd, maar is vanwege deze jurisprudentie wel te beschouwen als geldend recht.

Al lijken de toegangsverboden nog zo op publieke sancties, de voorgaande beschrijving van de verschillende juridische grondslagen laat zien dat het in juridische zin gaat om privaatrechtelijke sancties. Ondernemers in het semipublieke domein kunnen anderen de toegang ontzeggen op basis van hun privaatrechtelijke bevoegdheden met als doel schade in de toekomst te voorkomen, of omdat zij gezien ervaringen met de betrokkene in de toekomst geen zaken meer willen doen met deze persoon. Dat zijn vanuit het privaatrechtelijke kader - het beginsel van schadevoorkoming, de exclusiviteit van het eigendomsrecht en de contractsvrijheid - gerechtvaardigde doelstellingen (Van Rooij 2018).

Dat neemt niet weg dat de toegangsverboden wel bestraffend kunnen aanvoelen voor de betrokkene en de ondernemers beogen wellicht ook leed toe te voegen. Schuilenburg (2012) spreekt ook wel van 'quasistrafrecht' en Wierenga en Brouwer (2014, p. 83) noemen dit buitenwettelijk strafrecht. Vanuit een juridisch perspectief meen ik echter dat de verbanning nauwer verwant is aan de doelstellingen van het privaatrecht dan aan de vergeldende functie van het strafrecht. Een belangrijk verschil met het strafrecht is dat het legaliteitsbeginsel vergt dat straffen opgelegd worden op basis van algemeen verbindende wetgeving waar iedere burger gelijk aan gebonden is. ${ }^{16}$ Burgers kunnen zich niet onttrekken aan de regels en strafsancties die op de overtreding daarvan staan. Dat is anders in het semipublieke domein, want 
de regels steunen hier op vrije wilsvorming tussen partijen en de keuze om de betreffende winkel, horecagelegenheid of zaak van de ondernemer te bezoeken. De toegangsverboden zijn niet buitenwettelijk, want het Burgerlijk Wetboek (BW) en de Wp 2000 bieden een adequate juridische grondslag.

Bovendien worden ook de strafrechtelijke gebiedsverboden gekwalificeerd als preventieve maatregelen, gericht op herstel en bescherming van de maatschappij. ${ }^{17}$ Gebiedsverboden in de vorm van bevelen van de burgemeester worden door de bestuursrechter eveneens niet aangemerkt als een criminal charge in de zin van artikel 6 van het Europees Verdrag tot bescherming van de rechten van de mens en de fundamentele vrijheden (EVRM). ${ }^{18} \mathrm{Ik}$ zie geen reden om de private toegangsverboden - die zelfs nog minder verstrekkend zijn, omdat geen sprake is van uitsluiting tot de openbare ruimte - als bestraffend te beschouwen. De Hoge Raad kwalificeerde een stadionverbod niet als een criminal charge, vanwege de beperkte inmenging in de bewegingsvrijheid en omdat aan de overtreding van een KNVB-stadionverbod geen vervangende hechtenis is verbonden. Het voorgaande leidt mij tot de conclusie dat het vanuit een juridisch perspectief passender is de toegangsverboden tot het semipublieke domein te kwalificeren als preventief privaatrecht en niet als buitenwettelijk of quasistrafrecht.

\section{Juridische waarborgen tegen misbruik en willekeur}

In privaatrechtelijke rechtsverhoudingen heeft het beginsel van partijautonomie tot gevolg dat ondernemers in het semipublieke domein primair zelf bepalen met wie zij zakendoen en wie zij liever niet binnenlaten, bijvoorbeeld omdat de betrokkene bekendstaat als een notoire overlastgever. Toegangsverboden staan echter op gespannen voet met het belang dat burgers hebben bij vrije beweging in het publieke domein en de toegankelijkheid van belangrijke publieke voorzieningen en social resources die daar worden aangeboden (Von Hirsch \& Shearing 2002). Het exclusieve huisrecht en contractsvrijheid

17 Ten aanzien van art. 38v Sr: Kamerstukken // 2010/11, 32551, 3, p. 9-10. De beslissing over vervangende hechtenis bij overtreding van het gebiedsverbod is twijfelachtiger, zie p. 15 n.a.v. reactie van de Raad voor de rechtspraak.

18 Bijv. ABRvS 4 mei 2011, ECLI:NL:RVS:2011:BQ3446. 
rechtvaardigen weliswaar dat een ondernemer in het semipublieke domein een toegangsverbod uitvaardigt in het geval van overlast, maar welke juridische waarborgen zorgen voor bescherming tegen misbruik en willekeur?

Beheerders hebben een gerechtvaardigd belang bij het voorkomen van schade en overlast, maar zij moeten hierbij bepaalde juridische waarborgen in acht nemen. De beheerder mag met het toegangsverbod geen onrechtmatige daad jegens de betrokken overlastgever plegen, en dat betekent dat de maatregel geen inbreuk mag maken op een recht van een ander en niet in strijd mag zijn met de wet en de maatschappelijke zorgvuldigheidsnorm. ${ }^{19}$ Als het gaat om een toegangsverbod in de uitvoering van een contract, dan zijn de eisen van de redelijkheid en billijkheid toepasselijk. ${ }^{20}$ Aan de hand van deze privaatrechtelijke normen kan de rechtmatigheid van opgelegde sancties worden getoetst. Er zijn vervolgens verschillende remedies om onrechtmatigheid te herstellen of verder te voorkomen, zoals een schadevergoeding of een verbod om de sanctie nog verder uit te voeren.

Uit lagere rechtspraak over toegangsverboden en andere vormen van uitsluiting van publieke goederen en diensten is een aantal concrete begrenzingen te destilleren (Van Rooij 2017a, p. 457-493). In de eerste plaats is dat het verbod van willekeur; een beheerder mag niet zonder reden iemand uitsluiten van publieke goederen en diensten. Daarmee verschilt het semipublieke domein principieel van de woning en andere besloten ruimtes. De beheerder dient aannemelijk te maken dat het verweten overlast of wangedrag daadwerkelijk heeft plaatsgevonden en welke dreiging nog bestaat. De sanctie zal bovendien in verhouding moeten staan met de ernst van de overlast en het afkeurenswaardige en verwijtbare karakter van de gedraging. Dit is een proportionaliteitstoets.

Daarnaast wordt de beschikbaarheid van alternatieven meegenomen als een relevante factor in de belangenafweging: als de betrokkene voor hem belangrijke goederen en diensten nog elders kan genieten, dan zal uitsluiting niet snel onrechtmatig zijn. Zo overwoog de Rechtbank Middelburg in een zaak over een collectief horecaverbod naar aanleiding van een vechtpartij met carnaval dat het verbod gold voor 27 van de 103 horecazaken in de gemeente Hulst en dat de betrokkene 
zelf niet woonachtig was in die gemeente. Daaruit leidt de rechtbank af dat de betrokkene niet in zodanige mate in zijn persoonlijke vrijheden is beperkt dat er grond bestaat voor een schadevergoeding. ${ }^{21}$ Bovendien is van belang welke maatschappelijke functie de verboden plaats heeft: een toegangsverbod tot een horecagelegenheid zal minder snel onrechtmatig zijn dan een ontzegging van toegang tot een apotheek of moskee, om maar twee uitersten te noemen. In een zaak over een moskeeverbod wegens opruiend gedrag en bedreigingen die zouden zijn geuit naar de bestuurders, stelde het Gerechtshof Den Haag vast dat gezien hun jarenlange gewoonte van moskeebezoek de appellanten in beginsel het recht hadden om de moskee te betreden en daar hun geloof te belijden. ${ }^{22}$ De stichting zou zich vervolgens schuldig maken aan willekeur als de vaste bezoekers zonder zwaarwegende redenen de toegang tot de moskee wordt ontzegd.

Verder moeten private beheerders dwingende wetsbepalingen in acht nemen. Dit type bepalingen kan niet in een contract worden 'weggeregeld'. Particulieren zijn bijvoorbeeld niet bevoegd tot het gebruik van fysiek geweld om de ander de regels te doen naleven, gebruik van geweld is strafbaar. Contractuele afspraken die van deze norm afwijken, zijn nietig vanwege strijd met de openbare orde en goede zeden. ${ }^{23}$ Ook de registratie van toegangsverboden in databases en de uitwisseling van deze gegevens tussen ondernemers en de overheid moeten conform de dataprotectiewetgeving plaatsvinden (Van Rooij 2017b). ${ }^{24}$ De Algemene wet gelijke behandeling (AWGB) bepaalt dat ondernemers bij het verlenen van toegang tot goederen en diensten en bij het uitvoeren of beëindigen van overeenkomsten niet mogen discrimineren. ${ }^{25}$ Vooral in het uitgaansleven is discriminatoir deurbeleid al jaren een terugkerend thema in de oordelen van het College voor de Rechten van Mens. Als een toegangsverbod wordt opgelegd wegens daadwerkelijke overlast is dat niet in strijd met de gelijkebehandelingswetgeving, maar het is wel problematisch als het toegangsverbod is gebaseerd op vooroordelen (profilering), of als de private sancties alleen feitelijk worden opgelegd in het geval van personen met een bepaalde

21 Rb. Middelburg 29 maart 2009, ECLI:NL:RBMID:2009:BK9255 (Horecaverbod Hulst).

22 Hof Den Haag 16 juni 2009, ECLI:NL:GHSGR:2009:BK4987 (Moskeeverbod), r.o. 7.4-7.5.

23 Art. 3:40 BW.

24 De Wet bescherming persoonsgegevens, met ingang van 25 mei 2018: de Algemene verordening gegevensbescherming, Verordening (EU) 2016/679.

25 Art. 7 lid 1 aanhef en onder a jo. art. 1 jo. art. 2 AWGB. 
etnische achtergrond (Van Rooij 2018) ${ }^{26}$ Dit komt neer op een recht op gelijke toegang tot het semipublieke domein.

\section{Rechtsbescherming van de verbannen burger}

Vervolgens is het de vraag of een betrokkene voldoende toegang heeft tot rechtsbescherming, zodat gecontroleerd kan worden of partijen hebben gehandeld conform die hiervoor geschetste kaders. De toegangsverboden worden doorgaans opgelegd zonder tussenkomst van de rechter. Aangezien de toegangsverboden steunen op een privaatrechtelijke juridische basis, kan de betrokkene zich na oplegging tot de burgerlijke rechter wenden. ${ }^{27}$

Er zijn relatief weinig civielrechtelijke uitspraken bekend waarin mensen opkomen tegen (collectieve) toegangsverboden in het semipublieke domein. Eén mogelijke verklaring is dat de kosten van de civielrechtelijke procedure een te hoge drempel zijn (CBS 2013). De Raad voor Rechtsbijstand verleent geen toevoeging voor rechtsbijstand in zaken die de vrijetijdsbesteding betreffen, zoals een civiele procedure tegen een stadionverbod. ${ }^{28}$ Een tweede verklaring is dat een deel van de ontzeggingen wordt opgelegd aan personen die de Nederlandse taal niet machtig zijn. Schuilenburg signaleert ten aanzien van winkelverboden in den Haag dat het vooral gaat om Oost-Europeanen (Schuilenburg 2012, p. 335).

Een laatste verklaring is gelegen in de geringe kans op succes. In de bekende uitspraken loopt het zelden gunstig af voor de betrokkene. Ik zie, vooral in voetbalzaken, dat rechters vanwege de open formulering van de algemene voorwaarden een zeer marginale toets uitvoeren. De rechter laat het bijvoorbeeld aan de KNVB zelf om te beoordelen wanneer sprake is van 'voetbalgerelateerd wangedrag' en toetst deze kwalificatie heel terughoudend. ${ }^{29}$ Alleen bij flagrante fouten beslist de burgerlijke rechter in het voordeel van het individu.

Ik meen dat dit een onjuiste gang van zaken is. De burgerlijke rechter zou zich bij de beoordeling van private toegangsverboden in het semipublieke domein en de uitleg van de open normen in de overeen-

26 Bijv. Commissie Gelijke Behandeling, oordeel 2005-143 (Tassencontrole Ethiopische klant). 27 Dat geldt ook voor de reis- en verblijfsverboden in het openbaar vervoer, CBb 16 augustus 2017, ECLI:NL:CBB:2017:349 en 350.

28 ABRvS 18 juli 2012, ECLI:NL:RVS:2012:BX1839.

29 Bijv. Rb. Overijssel 11 februari 2016, ECLI:NL:RBOVE:2016:434, r.o. 4.6. 
komst actief moeten opstellen, aangezien het hier gaat om een consumentenrelatie. Bezoekers van winkels, horeca en evenementen en reizigers hebben vrijwel geen onderhandelingsruimte over de gedragsregels in algemene voorwaarden en huisregels en de daaraan gekoppelde private sancties. In het geval van collectieve verboden is bovendien mogelijk sprake van economisch overwicht. Uit het Océanoarrest van het Hof van Justitie en het Telefoonabonnement II-arrest van de Hoge Raad is af te leiden dat de rechter zich bij beoordeling van een consumentenovereenkomst actief dient op te stellen en ambtshalve dient te toetsen of de bedingen waarover de consument niet kon onderhandelen niet oneerlijk zijn (Ancery 2013). ${ }^{30}$

Naast de burgerlijke rechter fungeren klachtencommissies als een vorm van controle op het uitreiken van toegangsverboden. Klachtencommissies die fungeren als controle op dienstverlenende private of semipublieke organisaties zijn een vorm van 'informele rechtspleging' of 'particuliere rechtspraak' (Ippel 1989, p. 24-25). Zo kan een voetbalsupporter bezwaar maken bij de Commissie stadionverboden van de KNVB tegen een landelijk stadionverbod (Wierenga \& Brouwer 2014, p. 114-116). ${ }^{31}$ Voor collectieve horeca- en winkelontzeggingen zijn op lokaal niveau commissies ingesteld. Het nieuwe modelprotocol winkelverboden van het Centrum voor Criminaliteitspreventie en Veiligheid (CVV) gaat uit van een landelijke commissie. ${ }^{32}$ In het openbaar vervoer kunnen geschillen die voortvloeien uit de vervoerovereenkomst worden voorgelegd aan de Geschillencommissie Openbaar Vervoer. $^{33}$

Het voordeel van dit type commissies is dat zij een laagdrempelige vorm van controle bieden. Als het gaat om de klachtencommissies die functioneren in het kader van een publiek-privaat samenwerkingsverband, is een voordeel dat zowel de verschillende publieke als de verschillende private ketenpartners vertegenwoordigd zijn, waardoor partners elkaar onderling kunnen controleren. De Commissie stadionverboden bestaat bijvoorbeeld uit twee (straf)rechters, een oud-politiecommandant en een voormalige veiligheidscoördinator, die voor-

30 HvJ EG 27 juni 2000, C-240/98 t/m C-244/98, NJ 2000/730 (Océano Grupo Editorial/Murciano Quintero). HR 12 februari 2016, ECLI:NL:HR:2016:236 (Telefoonabonnement II), r.o. 3.17 .

31 Art. 11.1 KNVB Standaardvoorwaarden. Deze commissie moet worden onderscheiden van de tuchtcommissie en de commissie van beroep, die oordelen over wangedragingen van sporters op het veld.

32 CCV-modelprotocol, p. 8, te raadplegen via: www.veiligondernemenbeginthier.nl. 33 Art. 12 lid 1 en 21 lid 6 Wp 2000. 
heen in dienst was van een betaaldvoetbalorganisatie (CIV 2016, p. 51).

Een nadeel is dat de toetsingskaders van de commissies die oordelen over toegangsverboden in het semipublieke domein op voorhand onduidelijk zijn of erg uiteenlopen. De winkel- en horecacommissies lijken uitsluitend te zijn geënt op de controle van de gegevensverwerking. Ook de Commissie stadionverboden let volgens het reglement in het bijzonder op de rechtmatigheid van gegevensverwerking. ${ }^{34}$ Desgevraagd geeft de KNVB aan dat de commissie ook kijkt naar de juistheid van de feiten, aan de hand van foto- en videobewijs en getuigenverklaringen (Van Rooij 2017a, p. 557). De KNVB benadrukt bovendien dat de commissie bestaande (civielrechtelijke) jurisprudentie meeneemt in de beslissing en de rechtmatigheid van het opgelegde stadionverbod beoordeelt. Dit is echter niet terug te vinden in het gepubliceerde reglement.

Een tweede nadeel is dat de procedures bij de verschillende commissies in de hoofdregel geheel schriftelijk zijn. Gebrek aan een mondelinge ronde bij de Commissie stadionverboden wordt als een gemis ervaren door enkele advocaten die voetbalsupporters bijstaan, omdat supporters vaak wel de behoefte hebben om hun verhaal te doen (Van Rooij 2016). Supporters hebben dan niet het idee dat ze gehoord zijn en dat bedreigt de acceptatiegraad van de sancties (Bos 2010,

p. 29-30).

De Geschillencommissie Openbaar Vervoer is op beide punten een uitzondering. Dit is een wettelijke commissie; de Wp 2000 schrijft voor dat er een kenbaar reglement wordt vastgesteld met regels over de bevoegdheid, procedurevoorschriften en geheimhouding. Ook de toetsingsmaatstaven zijn helder. In het reglement is geregeld dat de commissie de rechtmatigheid toetst aan de hand van de algemene voorwaarden, Verordening (EU) 1371/2007 over de rechten en plichten van reizigers en de eisen van redelijkheid en billijkheid. ${ }^{35}$ Het reglement voorziet ten slotte in een mondelinge ronde.

Afsluitend meen ik dat de klachtencommissies van toegevoegde waarde zijn als een laagdrempelig filter om fouten te kunnen herstellen. Het is echter onbekend of zij deze functie momenteel ook daadwerkelijk vervullen. Meer transparantie over het toetsingskader kan de 
legitimiteit van de commissies verbeteren. De verbetering van hoor en wederhoor kan bovendien de acceptatiegraad en daarmee de legitimiteit van de toegangsverboden verbeteren. Met deze versterkingen kunnen de klachtencommissies een volwaardige rechtsbeschermende functie innemen, zij het dat het - net als bestuursrechtelijk bezwaar niet kan worden gelijkgesteld met onafhankelijke rechtspraak.

\section{Slot}

De toegangsverboden in het semipublieke domein lijken op het eerste gezicht op bestuurlijke en (quasi)strafrechtelijke sancties, maar in juridische zin zijn zij privaatrechtelijk van aard. Dat de overheid private beheerders faciliteert met informatie en feitelijke bijstand verandert niets aan het private karakter van de sancties. In vergelijking met de bestuursrechtelijke en strafrechtelijke normen en rechtsbescherming lijkt het individu minder beschermd, maar dat is vanuit een juridisch perspectief te rechtvaardigen vanuit het uitgangspunt van partijautonomie, contractsvrijheid en het exclusieve karakter van het huisrecht. Daar komt bij dat de feitelijke gevolgen van een toegangsverbod minder diep ingrijpen in de bewegingsvrijheid en toegang tot publieke voorzieningen in vergelijking met publiekrechtelijke gebiedsverboden die gelden voor de gehele publieke ruimte, waaronder de openbare weg.

Maar ook in het privaatrechtelijke kader is de oplegging van private toegangsverboden aan bepaalde juridische randvoorwaarden gebonden. Bij de beoordeling van de rechtmatigheid van de toegangsverboden moet gewicht toekomen aan de maatschappelijke functie van het verboden domein, de beschikbaarheid van alternatieven, proportionaliteit van de sanctie en het belang bij gelijke toegang tot publieke diensten en goederen. Het is vervolgens belangrijk dat een betrokkene toegang heeft tot een procedure waarin wordt vastgesteld wat er gebeurd is en of de sanctie proportioneel en rechtmatig is. Die controle kan plaatsvinden bij de burgerlijke rechter, die zich ter bescherming van de consument actief opstelt, en bij klachtencommissies, mits deze transparant opereren en met inachtneming van hoor en wederhoor. 


\section{Literatuur}

Ancery 2013

A. Ancery, 'Ambtshalve toepassing van consumentenbeschermend EU-recht', Maandblad voor Vermogensrecht 2013, afl. 12, p. 329-339.

\section{Bos 2010}

J.G.H. Bos (m.m.v. E.J. van der Torre), Organiseren van veiligheid in het betaald voetbal, Den Haag: COT 2010.

\section{Brouwer \& Schilder 2007}

J.G. Brouwer \& A.E. Schilder, 'Gebiedsontzeggingen in het systeem van het openbare-orderecht', JBplus 2007, p. 154-167.

\section{CBS 2013}

Centraal Bureau voor de Statistiek (CBS), Burgerrechter behandelt minder zaken, 13 januari 2013, www.cbs.nl, thema veiligheid en recht.

\section{2016}

Centraal Informatiepunt Voetbalvandalisme (CIV), Jaarverslag CIV Voetbal en veiligheid. Seizoen 2015/2016, Utrecht: CIV 2016.

\section{2017}

Centraal Informatiepunt Voetbalvandalisme (CIV), Jaarverslag CIV Voetbal en veiligheid. Seizoen 2016/2017, Utrecht: CIV 2017.

\section{Von Hirsch \& Shearing 2002}

A. von Hirsch \& C. Shearing, 'Exclusion from public space', in: A. von Hirsch, D. Garland \& A. Wakefield (red.), Ethical and social perspectives in situational crime prevention, Oxford: Hart Publishing 2002, p. 77-96.

\section{Hoogenboom \& Muller 2002}

A.B. Hoogenboom \& E. Muller, Voorbij de dogmatiek: publiekprivate samenwerking in de veiligheidszorg, Den Haag: COT (Politie \& Wetenschap) 2002.

\section{Ippel 1989}

P.C. Ippel, Reacties op rechtsbescherming in twee dienstverlenende organisaties: een rechtssociologische studie (diss. Amsterdam VU), Zwolle: W.E.J. Tjeenk Willink 1989.

\section{Jue-Volker 2016}

B.W.A. Jue-Volker, 'Gebiedsverboden in het bestuursrecht en strafrecht: uitbreiding of wildgroei?', in: Openbare-orderecht in ontwikkeling (Jonge VAR-reeks 14), Den Haag: Boom juridisch 2016, p. 61-117.

\section{Kabel 2007}

J.C.C. Kabel, 'Handelsinformatiebureaus, particuliere onderzoeksbureaus en zwarte lijsten', in: J.M.A. Berkvens \& J.E.J. Prins, Privacyregulering in theorie en praktijk, Deventer: Kluwer 2007. 


\section{Van Rooij 2014}

A.E. van Rooij, 'Private ordehandhaving op voor publiek toegankelijke plaatsen. Grondrechtelijke grenzen collectieve winkel- en horecaontzeggingen', in: J.G. Brouwer \& A.E. Schilder (red.), Van een andere orde. Over private ordehandhaving, Den Haag: Boom Juridische uitgevers 2014, p. 51-80.

\section{Van Rooij 2016}

A.E. van Rooij, 'Rechtsbescherming bij publiek-private handhaving van de openbare orde. Van fragmentatie naar integratie', in: Openbare-orderecht in ontwikkeling (Jonge VAR-reeks 14), Den Haag: Boom juridisch 2016, p. 119-173.

\section{Van Rooij 2017a}

A.E. van Rooij, Orde in het semipublieke domein. Particuliere en publiek-private orderegulering in juridisch perspectief (diss.

Amsterdam VU), Den Haag:

Boom juridisch 2017.

\section{Van Rooij 2017b}

A.E. van Rooij, 'Privacy in het semipublieke domein. De bescherming van privacy bij publiek-private zorg voor openbare orde en veiligheid', Gemeentestem 2017/133.

\section{Van Rooij 2018}

A.E. van Rooij, 'Particuliere handhaving van de openbare orde. Over schadevoorkoming, goed beheerderschap en de bescherming van de toegankelijkheid van het semipublieke domein', Ars Aequi 2018, p. 174-178.

\section{Schuilenburg 2009}

M. Schuilenburg, 'De securisering van de samenleving. Over de relatie tussen veiligheidszorg, bestuur en quasistrafrecht', Krisis 2009, afl. 3, p. 6-22.

\section{Schuilenburg 2012}

M.B. Schuilenburg, Orde in veiligheid. Een dynamisch perspectief (diss. Amsterdam VU), Den Haag: Boom Lemma uitgevers 2012.

\section{Van Steden e.a. 2012}

R. van Steden e.a., 'Toezichthouders op de tram. Een studie naar de handhaving van het ov-verbod in Amsterdam en Rotterdam', Tijdschrift voor Toezicht (3) 2012, afl. 4, p. 9-21.

\section{Wesselink e.a. 2009}

L. Wesselink, M. Schuilenburg \& P. Van Calster, 'De collectieve winkelontzegging', Tijdschrift voor Veiligheid 2009, afl. 1, p. 6-19. 
26 Justitiële verkenningen, jrg. 44, nr. 2, 2018

\section{Wierenga \& Brouwer 2014}

A.J. Wierenga \& J.G. Brouwer, 'Bestrijding voetbalvandalisme via het privaatrecht', in: J.G.

Brouwer \& A.E. Schilder (red.), Van een andere orde. Over private ordehandhaving, Den Haag:

Boom Juridische uitgevers 2014, p. 81-134. 